they profess themselves socialists is ease without effort." "The advertisement of cheap and painless substitutes for war has been a recurring feature in the cycles of civilisation." We suspect that the author has a sense of humour hidden away somewhere and that perhaps he does not really mean all he says.

\section{IDENTIFICATION OF PLANTS.}

Name this Flower: A Simple Way of Finding out the Names of Common Plants without any Previous Knowledge of Botany. By Prof. Gaston Bonnier. Pp. xii $+33 I+$ plates 64 . (London and Toronto: J. M. Dent and Sons, Ltd.; New York: E. P. Dutton and Co., I9I7.) Price $6 s$, net.

THE desire to know the names of wild flowers is very widespread and by no means confined to those who take any particular interest in botanical science. For such as these there has been no easy book of reference. The simple books have all been written on botanical principles, and the science of plant classification underlies almost every so-called popular treatise.

Prof. Gaston Bonnier has fully realised this, and in producing his book, "Name this Flower," has achieved a really useful purpose. At first the botanist may be tempted to scoff and consider it a wasted effort, for the construction of the admirable keys must have been a most laborious work. But a little study reveals its great value, and a test with such difficult plants as sea holly or teazel shows how thoroughly the work has been done.

In writing the book Prof. Bonnier was largely influenced by the philosopher Ernest Bersot's "Letter on Botany," published among his "Reflections of a Moralist." "Botany," he says, "is one of the most deceitful of sciences. As flowers are so charming one imagines that it also must be charming; but how soon one is disillusioned! And why? Ah, why? Because the savants have thought about themselves and not about us. They have wished for a science complete in itself; and they have put each thing in its place without troubling to ascertain whether it would be easy for other people to find it there. How many times have I tried to become a botanist, and each time I have been vanquished."

Prof. Bonnier, by his exhaustive keys, well illustrated by line drawings, enables anyone to find out the names of plants without knowing anything of botany or of the principles of classification. The value of the book is enhanced by sixty-four plates of coloured illustrations, which represent the plants sufficiently adequately. A good deal of botanical and general information is also packed into the book, and it is very well indexed. Anyone using Prof. Bonnier's book carefully could scarcely fail to find that in so doing he had not only learnt the names of plants, but was also being impelled on the high road to become a botanist.

English students should be grateful to Prof. Boulger for this translation of Prof. Bonnier's excellent book.

$$
\text { NO. 2497, VOL. IOO] }
$$

\author{
LETTERS TO THE EDITOR.
}

[The Editor does not hold himself responsible for opinions expressed by his correspondents. Neither can he undertake to return, or to correspond with the writers of, rejected manuscripts intended for this or any other part of NATURE. No notice is taken of anonymous communications.]

\section{Unusual Rainbows.}

THE very interesting diagram sent to NATURE for August 30 (p. $5^{25}$ ) by Mr. Allan Low seems to exhibit a complete system of direct and reflected rainbows. The falling raindrops would be flooded with the direct light of the sun, forming the usual pair of bows. They would also be flooded with the light reflected from the surface of the sea; if the sea is not ruffled this latter light would be directed from a fairly concentrated! image of the sun, below the horizon. Thus it should show another pair of bows, the common axis of which is the prolongation of the line from the observer to this image of the sun; as that line points above the horizon, these bows should be more than a semicircle in extent. When the surface of the sea is ruffled, the blurred image of the sun will be so large that the colours in the bows will overlap, and only a broad white bow will appear, which would not be noticed. Fog bows are white for a different reason. The two systems of bows meet at points which must be equidistant from the sun and its image; for bows of the same radius these points must be on the horizon. The altitude of the anti-sun, the radius of the bow drawn to the horizon, and the horizon form a right-angled spherical triangle; thus the sine of half the angle between two bows where they intersect on the horizon is equal to the sine of the sun's altitude divided by the sine of the radius of the bow. With Mr. Low's estimated figures this would bring out the radius rather too small. J. L.

Cambridge, August 31 .

THE arcs of the third and fourth bows, so well described by Mr. Low in Nature of August 30, are, I think, undoubtedly due to the sun reflected from the ocean behind the ship.

Around a centre $\hat{O}$ describe two circles with radii of $4^{2} \mathrm{~mm}$. and $52 \mathrm{~mm}$. respectively. Then $7 \mathrm{~mm}$. above $O$ draw a horizontal line. This will represent the horizon, and the portions of the circles above this will be the primary and secondary bows due to the direct light of the sun. On a line from $O$, perpendicular to the horizontal line, take another point $P$, distant $\mathrm{r} 4 \mathrm{~mm}$. above $\mathrm{O}$, and describe circles about $\mathrm{P}$ with radii as before. The portions of these circles above the horizontal line will be the primary and secondary bows due to the reflected sun. It will be found that the figure thus obtained is very similar to that given by Mr. Low, except that he saw only small portions of the third and fourth bows. But I believe the sun's altitude must have been greater than $7^{\circ}$, for with that height only about one-sixth of the vertical radius of the primary bow would be below the horizon, and in his diagram about one-third is cut off. I have taken the radii of the primary and secondary bows as about $42^{\circ}$ and $52^{\circ}$, in round numbers.

Invermay, Hyde Park, Leeds, August $3 \mathrm{x}$.

$$
\text { C. T. WhitMell. }
$$

THERE seems to be a simple explanation of "An Unusual Rainbow" described by Mr. Low in NATURE of August 3o. If the sea was sufficiently calm there. would be from the point of view of the raindrops causing the rainbow, a real sun $7^{\circ}$ above the horizon 